\title{
ARTIGO
}

\section{AS POLÍticas de AÇÕES AFIRMATIVAS PARA A POPULAÇÃO NEGRA: A LEI 10639/03 E SEUS DISPOSITIVOS LEGAIS}

Affirmative action policies for the black population: Law 10.639/03 and its legal provisions

Las políticas de acciones afirmativas para la población negra: la Ley 10639/03 y sus

dispositivos legales

Zilmar Santos Cardoso

Universidade Estadual de Montes Claros - Brasil

\section{Resumo}

Neste artigo, discutimos o processo de criação de políticas de ações afirmativas para a população negra no cenário brasileiro, de forma a evidenciar sua importância no contexto educacional. O estudo tem por objetivo analisar a implementação das Diretrizes Curriculares Nacionais para a Educação das Relações Étnico Raciais nos cursos de formação docente de uma instituição pública de ensino superior no norte de Minas Gerais. Para isso tomamos como referência a Lei 10639/03 que instituiu a obrigatoriedade do ensino da História e Cultura Afro-Brasileira na Educação Básica, como uma das principais ações afirmativas para a população negra no campo educacional. Os resultados apontaram que as Diretrizes Curriculares para a Educação das Relações Étnico Raciais, não encontram-se em processo de implementação, as ações que vem sendo realizadas ainda são pontuais. Foi constatado problemas com uma inclusão normativa que depende de muitos passos para ser bem sucedida.

Palavras-chave: Ações afirmativas. Educação das relações étnico raciais. População negra.

\begin{abstract}
In this article, we discuss the process of creating affirmative action policies for the black population in the Brazilian scenario, in order to highlight its importance in the educational. The study aims to analyze the implementation of Curriculum Guidelines for Ethnic-Racial Relations Educational context in a public institution of higher education in the north of Minas Gerais. For this we took as Reference the Law 10639/03 that established the obligatoriness of the teaching of History and Afro-Brazilian culture in Basic Education, as one of the main affirmative actions for the black population in the education field.The results pointed out that
\end{abstract}


the Curricular Guidelines for Ethnic-Racial Relations Education are still in the process of implementation, the actions that have been undertaken are still pronpt. It found problems with a normative inclusion that depends on many steps to be successful.

Keywords: affirmative actions. Education of ethnic and racial relations. Black population.

\section{Resumen}

En este artículo discutimos el proceso de creación de políticas de acciones afirmativas para la población negra en el escenario brasileño, con la finalidad de evidenciar su importancia en el contexto educativo. El estudio tiene por objetivo analizar la implementación de las Directrices Curriculares Nacionales para la Educación de las Relaciones Étnico-Raciales en los cursos de formación docente de una institución pública de enseñanza superior en el norte de Minas Gerais. Para ello, tomamos como referencia la Ley 10639/03 que instituyó la obligatoriedad de la enseñanza de la Historia y Cultura Afro-Brasileña en la Educación Básica como una de las principales acciones afirmativas para la población negra en el campo educativo. Los resultados han revelado que las Directrices Curriculares para la Educación de las Relaciones Étnico-Raciales se encuentran en proceso de implementación, las acciones que se vienen realizando todavía son puntuales. Se constataron problemas con una inclusión normativa que depende de muchos pasos para tener éxito.

Palabras clave: Acciones afirmativas. Educación de las relaciones étnico-raciales. Población negra.

\section{Introdução}

As políticas públicas de ações afirmativas visam atender aos grupos estigmatizados, com a intenção de promover o acesso aos bens sociais e materiais. De acordo com Guimarães (2008), podemos chamar de ações afirmativas toda e qualquer política pública que tenha como finalidade promover aos membros desses grupos, e que sofrem preconceitos e discriminações, não só o acesso, mas também condições para permanência na educação, no mundo do trabalho e nos bens sociais de forma mais ampla.

O estudo tem por objetivo analisar a implementação das Diretrizes Curriculares Nacionais para a Educação das Relações Étnico Raciais nos cursos de formação docente de uma instituição pública de ensino superior no norte de Minas Gerais. Discutimos o contexto de criação e implementação de políticas públicas de ações afirmativas para a população negra, considerando a Lei 10639/03, como uma das principais ações afirmativas no campo educacional para esse segmento da população brasileira. Essa Lei alterou os artigos 26 e 79 da atual LDB 9.394/96 tornando obrigatório, em todo o território nacional, o ensino de História e Cultura Afro-Brasileira na Educação Básica e instituiu no calendário escolar o dia 20 de 
novembro como "Dia da Consciência Negra". Em 2008, o artigo 26 da LDB foi novamente alterado pela Lei 11.645/08 com o propósito de acrescentar a História e a Cultura dos Povos Indígenas no currículo escolar. O foco do nosso trabalho é direcionado especificamente às diretrizes inicialmente determinadas pela Lei 10.639/03.

As novas diretrizes do artigo 26-A da LDB 9.394/96 incidem consequentemente na formação inicial e continuada de professores e profissionais da educação. A regulamentação do cumprimento de tais alterações em todos os níveis e modalidades de ensino, foi estabelecida pela Resolução CNE/CP 01/2004, que instituiu as Diretrizes Curriculares Nacionais para a Educação das Relações Étnico-Raciais e para o Ensino de História e Cultura Afro-Brasileira e Africana (DCNERER) ${ }^{1}$.

O trabalho está organizado em três seções. Na primeira, refletimos acerca do contexto de criação de políticas públicas para população negra; em seguida, discutimos e evidenciamos a necessidade dessas ações no campo educacional; e, finalmente, em formato de síntese, em função do caráter desse trabalho, apresentamos a pesquisa e as análises e reflexões que o estudo possibilitou.

No Brasil, as iniciativas no campo das políticas públicas de ações afirmativas são bem recentes. De acordo com Gonçalves (2008), as ações governamentais nesse sentido começaram a ser implantadas na década de 1980, no fim do regime autoritário, sob influência do projeto reformista da Nova República. A autora observa:

Mais recentemente, com a adoção das chamadas políticas neoliberais que visavam reduzir o escopo de intervenção pública, o Estado brasileiro vem apoiando políticas particularistas, entre elas as políticas afirmativas, em várias áreas; saúde, educação, mercado de trabalho, para os grupos minoritários, entre eles as populações negras. (GONÇALVES, 2008, p. 273).

As políticas de ações afirmativas para a população negra geram opiniões opostas e inconciliáveis no meio acadêmico e na sociedade como um todo, ocasionando manifestações de apoio e de oposição. Têm aqueles que apoiam, porque consideram que os grupos contemplados pelas ações afirmativas foram historicamente destituídos de oportunidades e que é obrigação do Estado e da sociedade reparar tal situação, promovendo assistência e oportunidades de acesso e inclusão desse segmento aos bens sociais. Numa visão oposta, estão aqueles que acreditam que este tipo de ação acirrará ainda mais a separação das classes

\footnotetext{
${ }^{1}$ As DCNERER foram aprovadas por meio dos argumentos do Parecer CNE/CP 03/2004, cuja relatora foi a professora Petronilha Beatriz Gonçalves e Silva, da Universidade Federal de São Carlos (UFSCAR).
} 
sociais e etnias baseadas em critérios de cor, causando a fragmentação do povo e a instauração de conflitos raciais, até então inexistentes (GONÇALVES, 2008).

Na visão de Souza (2006), uma análise sobre as políticas públicas possibilita a compreensão do problema para o qual a política de ações afirmativas foi desenhada, como também seus possíveis conflitos, a trajetória seguida e o papel dos sujeitos, grupos e instituições que serão envolvidos nas decisões e ações que serão demandadas. As ações afirmativas voltadas para a população negra no Brasil têm suas raízes no contexto sóciohistórico, decorrente do processo de colonização e escravização da população nativa e de outras oriundas de diferentes pontos do continente africano. Conforme Gonçalves (2008), foram milhões de pessoas trazidas à força para trabalhar sob o regime escravista em terras brasileiras.

Esse regime permaneceu durante séculos e suas consequências ainda se refletem no contexto social contemporâneo, devido à herança histórica de discriminação racial que, mesmo após a abolição da escravidão, mantém a exclusão. Os negros não participaram dos resultados dos processos produtivos e econômicos da sociedade brasileira ${ }^{2}$. Para os ativistas do movimento negro e alguns estudiosos da temática, o processo abolicionista não significou a integração econômica, cultural e social dos negros no mercado produtivo; pelo contrário, intensificou sua marginalização diante da ausência de empregos e de políticas voltadas à subsistência dos negros.

A substituição do trabalho escravo pelo trabalho livre ocorreu de forma excludente. Mário Theodoro, professor e estudioso da temática, esclarece que

mecanismos legais, como a Lei de Terras, de 1850, a Lei da Abolição de 1888 , e o processo de estímulo à imigração forjaram um cenário no qual a mão de obra negra passa de uma condição de força de trabalho escravo para mão de obra excedente, sobrevivendo, em sua maioria, dos pequenos serviços ou da agricultura de subsistência. (THEODORO, 2008, p. 15).

Embora alguns estudiosos, como Theodoro (2008), apontassem que os escravizados exerciam várias profissões e que havia "mão de obra escrava mais qualificada", com o fim da escravidão, o contingente de trabalho foi sendo substituído pelos imigrantes europeus, que recebiam incentivos do governo brasileiro para se instalarem no país.

\footnotetext{
2 O livro clássico de Florestan Fernandes - A integração dos negros na sociedade de classes - é referência no tratamento desta questão no Brasil.
} 
Essa política de imigração à época estava alicerçada na perspectiva da tão conhecida teoria do "branqueamento" da população brasileira pelo processo de miscigenação, fato que, segundo o autor, era considerado como condição imprescindível para o desenvolvimento do país - processo que permitiu uma grande valorização do europeu, acentuando a perda do lugar no mercado de trabalho pela população negra. Nesse contexto, Theodoro salienta que, "essa perda significou a perpetuação de uma situação de pobreza e miséria. Sem lugar nos setores econômicos mais dinâmicos, o negro vai buscar espaços nos meandros e interstícios possíveis: os pequenos serviços, o trabalho precário, etc.” (2008, p. 38).

O autor salienta, ainda, que a "consolidação da visão, de cunho racista, de que o progresso do país só se daria com o branqueamento, suscitou a adoção de medidas e ações governamentais que findaram por desenhar a exclusão, a desigualdade e a pobreza que se reproduzem no país, até os dias atuais" (THEODORO, 2008, p. 15).

A literatura sobre a questão racial brasileira indica que, para a elite majoritária da política nacional, a situação não seria somente a substituição do negro como mão de obra, mas sua completa diluição como grupo racial no contexto nacional. Conforme Theodoro (2008), a presença da população negra no país era vista como um obstáculo que precisava ser superado, sendo sua gradativa extinção realizada pelo processo do branqueamento.

Concordando com Theodoro (2008), Jaccoud (2008, p. 45) assinala que, no Brasil, o racismo se desenvolve associado ao processo de escravização, mas ganha força e se "estrutura como discurso, com base nas teses de inferioridade biológica dos negros, e se difunde no país como matriz para a interpretação do desenvolvimento nacional”. Para se desenvolver, o Brasil precisava ser constituído por uma população branca, com os padrões europeus, considerada intelectualmente superior.

Os estudos históricos demonstram que a herança da prática escravista registrou no inconsciente coletivo a noção da inferioridade da população negra, surgindo um preconceito e discriminação racial que se manifesta de diversas formas na sociedade brasileira. Segundo Jaccoud, as teorias sobre raça e o propósito do branqueamento perduram até os anos 1930 do século XX. No entanto, a valorização do processo de miscigenação e do mulato persistia e continuava reforçando o ideal do branqueamento como um projeto social e pessoal. As críticas a esse ideal preconizado só ganharam repercussão no final do século $\mathrm{XX}$, com as crescentes movimentações e constantes denúncias do movimento negro.

Pereira (2013) esclarece que o ideal do projeto nacional brasileiro em relação à questão racial gerou muitos conflitos e discussões teóricas sobre sua viabilidade e caminhos 
que deveriam ser seguidos para seu alcance, não somente entre os "estudiosos", mas também pelo movimento negro que, desde o início do século $\mathrm{XX}$, promovia congressos, publicava textos em jornais, organizava-se para discutir essas questões em defesa da população negra.

Progressivamente, no decorrer dos anos 1920 e 1930, as desigualdades entre os grupos sociais deixam de ser explícitas, pela dimensão biológica, e passam a ser vistas pelos aspectos culturais e sociais. Nesse sentido, a utilização do conceito de raça na interpretação da sociedade brasileira vai sendo relacionada com as questões culturais e sociais.

O cenário brasileiro, a partir dos anos 1930, ganhou nova roupagem com o surgimento da ideologia da democracia racial; a elite política à época suscita essa nova perspectiva para lidar com a questão da identidade da população brasileira, a "teoria da democracia racial". Segundo Jaccoud (2008, p. 50), “emerge um pensamento racial que destaca a dimensão positiva da mestiçagem no Brasil, e afirma a unidade do povo brasileiro como produto das diferentes raças e cuja convivência harmônica permitiu ao país escapar dos problemas raciais observados em outros países”.

Kabengele Munanga considera que Gilberto Freyre, com a obra "Casa grande e senzala" - ao contrário de outros autores à época, como Nina Rodrigues, que considerava que a mistura da raça branca com as raças não puras degradaria ainda mais a população brasileira - transforma a mestiçagem numa grande vantagem, ao considerar o mito da origem da sociedade brasileira constituída pelas raças negra, branca e indígena, estabelecendo, assim, o mito da democracia racial que

[...] encobre os conflitos raciais, possibilitando a todos se reconhecerem como brasileiros e afastando das comunidades subalternas a tomada de consciência de suas características culturais que teriam contribuído para a construção e expressão de uma identidade própria. Essas características são "expropriadas", "dominadas" e "convertidas" em símbolos nacionais pelas elites dirigentes. (MUNANGA, 2008, p. 77).

Dessa forma, o autor pondera que essa nova perspectiva tem uma grande repercussão e consolidação na sociedade brasileira, estabelecendo a visão de uma convivência harmoniosa entre as pessoas de todas as classes sociais e grupos étnicos, possibilitando às elites dominantes condições de dissimular as desigualdades, fazendo com que os membros dos grupos não brancos não tivessem consciência da exclusão que sofriam e ainda sofrem.

A teoria da democracia racial, segundo Pereira (2013), foi desconstruída com uma pesquisa realizada pela Unesco, em meados de 1950, por solicitação de Arthur Ramos, um dos seus dirigentes à época, tendo como propósito apresentar os diversos fatores que levavam 
à harmonia ou desarmonia entre as relações raciais no Brasil. Tal pesquisa acabou provando o contrário do imaginário social preconizado nesse período. Alguns intelectuais responsáveis pela pesquisa, como Florestan Fernandes e Oracy Nogueira, constataram e denunciaram a existência das desigualdades raciais no Brasil, contrariando o interesse inicial do trabalho, demonstrando a existência do racismo e das grandes desigualdades raciais existentes no Brasil.

No entanto, a concepção da democracia racial bem como seus ideais foram impostos e permearam a sociedade brasileira até o final dos anos 1980, para além de todas as “importantes mudanças sociais, pelas quais passou o país"; durante essas três décadas, "seja no campo da modernização da economia, da urbanização, ou da ampliação das oportunidades educacionais e culturais", não foi possível observar "uma trajetória de redução das desigualdades raciais" (JACCOUD, 2008, p. 53). Esse olhar para as relações raciais nega o racismo tão presente no contexto histórico do Brasil, que vem excluindo os negros dos diversos espaços sociais. Para Alberti e Pereira (2005), essa questão tornou-se um dos principais problemas enfrentados pela militância do movimento nos anos 1970 .

A utopia da democracia racial é vista por Gonçalves (2007) como possibilidade que se abriu para a discussão e para o reconhecimento da diversidade cultural presente no contexto social brasileiro. Para a autora:

\begin{abstract}
A crítica ao mito da democracia racial simbolizada pelo mito das três raças negro, índio e branco - abre caminho para o reconhecimento das diferenças culturais e étnicas das populações brasileiras e possibilita uma reinterpretação do nosso mito que o coloca em seu devido lugar, ou seja, o de mito e não de um retrato real das relações raciais brasileiras. (GONÇALVES, 2007, p. 172).
\end{abstract}

Não temos a intenção de tecer uma imagem estereotipada da trajetória dos negros no Brasil pelo viés da servidão e do sofrimento, como sujeitos que aceitavam passivamente seu destino. Na literatura, encontramos diversos autores, como Mülher (2008) e Schwrarcz (2012), que descrevem a constante luta dos africanos e seus descendentes contra as mazelas a que eram submetidos em função do regime escravista, chamando a atenção para a importante participação dos negros nos movimentos abolicionistas, suas fugas e a intensa luta em busca de um lugar num meio social hostil e que não os enxergava como sujeitos de direitos, mesmo após a abolição. Schwarcz relata que os cativos inventaram condições para sobreviver na escravidão, por meio de negociações e conflitos. Utilizavam "da negociação, do blefe, da 
barganha e dos arranjos cotidianos" para superar os limites impostos pelo regime, sendo "às vezes bem, às vezes mal-sucedidos” (SCHWARCZ, 2012, p. 40). As negociações buscavam

[...] demandas por terra e melhores condições de trabalho como a defesa de uma vida espiritual lúdica e autônoma - o direito de tocar, cantar e brincar sem necessidade do consentimento do feitor, ou homenagear seus deuses na prática do candomblé sem a intromissão da polícia. [...] Mas, quando a negociação falhava, seja por intransigência do senhor ou impaciência do escravizado, abriam-se os caminhos para o conflito: fugas individuais e coletivas, formação de quilombos e, é claro, levante e revoltas escravas. (SCHWARCZ, 2012, p. 40).

Apesar de privados de sua liberdade, ainda assim os cativos buscavam formas de praticar suas religiões, de viverem conforme suas tradições culturais e de se organizarem em busca da almejada liberdade, participando intensamente na construção dos rumos da história do nosso país.

Observamos nos estudos de Silva, que, no período colonial, homens de cor tiveram participação nos conflituosos embates políticos que resultaram na Independência do Brasil e ocuparam destaque na política. A autora salienta, ainda, a participação, na primeira metade do século XIX, de intelectuais e políticos negros nas questões políticas do país à época (SILVA, 2006). Müller (2008) descreve que os estudos de Queiróz (1997) demonstram que, de alguma forma, antes ou depois do processo de abolição, escravos ou libertos, negros ou mestiços, encontraram formas de obter instrução ou de pelo menos incentivar seus descendentes a buscar instrução. A autora destaca a presença de referências intelectuais negras ou mestiças nesse período, como Cruz Lima, André Rebouças, Luíz Gama, José do Patrocínio, Machado de Assis, Lima Barreto, entre outros (MÜLLER, 2008). Esses fatos são importantes e contribuem para uma reinterpretação da trajetória dos afrodescendentes no Brasil.

O Estado e a política nacional, historicamente, não abriram espaço na agenda política para esse segmento da população brasileira, contribuindo para a inexistência de iguais oportunidades para negros e brancos. Na opinião de Oliveira,

[...] estamos no momento em que se inaugura uma nova fase em que o poder público que anteriormente recorreu a políticas para eliminar as populações negra e indígena, no momento, pressionado pelos movimentos sociais negro e indígena, reconhece a existência da discriminação racial e a necessidade de se promover a reparação junto a esses grupos, por meio das políticas de ação afirmativa e da criação de órgãos específicos para tratarem da questão. (OLIVEIRA, 2008, p. 6). 
As ações afirmativas para a população negra têm início na segunda gestão do governo de Fernando Henrique Cardoso (1999- 2003), com a promulgação do decreto n. ${ }^{\circ} 4228$, de maio de 2002, que instituiu o Programa Nacional de Ações Afirmativas no âmbito da administração do governo federal e vem se intensificando nos governos seguintes. O poder público vem regulamentando ações afirmativas para a população negra, em segmentos como a saúde, o trabalho, a educação e outros mais. Neste trabalho, apresentamos um recorte de estudo nas questões das políticas de ações afirmativas para a população negra no campo educacional, considerando o processo de implementação de leis específicas.

\section{As políticas de ações afirmativas no contexto educacional}

O ideal de branqueamento da população, que era predominantemente negra e indígena, que vigorou no século XIX e início do século $\mathrm{XX}$, contribuiu para excluir vários segmentos sociais. Os estudos de Müller (2008, p. 47) apontam que, [...] a elite nacional preocupada com o futuro do país acreditava que heterogeneidade racial e cultural impossibilitaria o progresso e o desenvolvimento [...]. Nesse ideal almejado para a população brasileira não havia espaço para os negros, considerados como raça inferior.

Conforme Ferreira (2013), historicamente, a educação considerada como possibilidade de transformação e ascensão social tem sido um tema caro para os ativistas e intelectuais do campo dos movimentos sociais negros. Nos estudos realizados sobre as questões raciais, vem sendo evidenciada a conflituosa situação de desigualdades entre negros e brancos, em vários contextos sociais, entre eles, a escola, que acaba por afirmar os estigmas sobre os negros e o racismo existente na sociedade.

Nessa direção, Santos (2007) considera que, a questão que merece mais atenção entre as relações raciais e educação

[...] consiste na reprodução do racismo na escola através de mecanismos intraescolares, nos quais instrumentos como o livro didático, o currículo, as relações professor-aluno e aluno-aluno etc., podem construir um conjunto ideológico de propagação dos valores etnocêntricos e reprodução de estigmas negativos contra o segmento negro". (SANTOS, 2007, p. 10).

Consideramos que houve um grande avanço em relação à publicação de livros e materiais didáticos nessa área, porém, em relação à análise dos livros didáticos que serão adotados e utilizados nas escolas - atividade que costuma ficar a cargo do professorado e da 
equipe pedagógica da escola -, em função da própria formação inicial que esses profissionais tiveram, pode incidir na escolha de livros que ainda privilegiam o etnocentrismo.

Essa situação pode fazer com que os alunos negros, sendo discriminados e não se enxergando representados nesse contexto, tenha o seu rendimento escolar prejudicado e, em consequência, desencadeia-se uma conflituosa interação com o sistema escolar. Cavalleiro constata que o sistema formal de educação não propicia elementos que proporcionem a “identificação positiva dos alunos negros com o sistema escolar” (2012, p. 35). Dessa forma, na competição do mundo das oportunidades, os negros e as negras estarão em condições de desigualdades, no contexto social brasileiro. Nessa linha de pensamento, Gomes argumenta:

$\mathrm{O}$ aprofundamento dessas questões aponta para a necessidade de repensar a estrutura, os currículos, os tempos e os espaços escolares. É preciso considerar que a escola brasileira, com sua estrutura rígida, encontra-se inadequada à população negra e pobre deste país. Nesse sentido não há como negar o quanto seu caráter é excludente. (GOMES, 2001, p. 86).

Para enfrentamento dessa realidade, a dinâmica pedagógica da escola precisa considerar e enxergar as diferenças cultural, socioeconômica, de raça, de gênero, de religião, ou seja, a diversidade social e cultural presente no Brasil e que ali se encontra representada, buscando formas de trabalhar com o currículo considerando tal diversidade. Assim, "a construção de práticas democráticas e não preconceituosas implica o reconhecimento do direito à diferença, e isso inclui as diferenças raciais” (GOMES, 2001, p. 87).

A Lei 10639/03 e as DCNERER apresentam-se como o fruto das lutas, ações e reivindicações do movimento negro que, de diversas formas, há muitas décadas, vem se empenhando com ações concretas contra o racismo, o preconceito e a discriminação racial em todo o âmbito social, especialmente o escolar. Representa uma grande conquista desse movimento social, ao regulamentar e oficializar no âmbito escolar o ensino sobre História e Cultura Afro-Brasileira, uma determinação que já estava posta na Constituição Brasileira, nos artigos 216 e 242, mas que ainda não se fazia presente no texto da legislação educacional - de forma clara e objetiva -, tornando oficial, no currículo escolar em todos os níveis de ensino, o estudo da História e da Cultura Afro-brasileira, uma prática que já vinha sendo realizada isoladamente por militantes do movimento social negro.

A luta pela inserção dessa temática no currículo escolar já vinha sendo colocada como pauta de debates no contexto acadêmico e nos órgãos governamentais por intelectuais ativistas do movimento negro, como descrito por Ferreira: 
Ativistas das organizações dos movimentos sociais negros e intelectuais, negros em sua maioria, que trabalham nas IES, em órgãos de gestão do governo federal e nas instâncias do Legislativo federal foram os principais sujeitos no processo que tornou obrigatório o ensino de conteúdos sobre história e cultura dos africanos e afrobrasileiros na educação básica e por consequência na educação superior. (FERREIRA, 2013, p. 11).

Silva Júnior esclarece que a Lei 10.639/03 não é uma legislação autônoma no sistema educacional. Ela alterou dois artigos da Lei de Diretrizes da Educação Básica (LDBEN 9394/96) e criou-se uma

[...] impressão de que se trata de uma reivindicação para que sejam incorporados os elementos da história da África e dos afro-brasileiros na disciplina história, quando, na verdade, se trata de reivindicação que o movimento negro sempre teve: os conteúdos e as práticas pedagógicas no Brasil precisam dialogar com a diversidade racial. (SILVA JÚNIOR, 2007, p. 432).

Nesse sentido, as alterações que ocorreram na LDB e os dispositivos legais desencadeados pela Lei 10639/03 representam um importante passo para que a diversidade étnico-cultural possa se fazer presente no ambiente escolar. Consideramos que os Parâmetros Curriculares Nacionais (PCN), que foram aprovados em 1998, com o objetivo de promover a inserção e discussão da pluralidade cultural no currículo oficial do ensino básico nas diversas áreas do conhecimento, foram um importante passo na direção de uma educação para a diversidade cultural. No entanto, não determina a obrigatoriedade da inclusão do estudo da História da África e dos Africanos, a luta dos negros no Brasil, a cultura negra brasileira e a história do negro na formação da sociedade brasileira em todo o currículo escolar, especialmente nas áreas de conhecimento, como história, artes e literatura, como proposto pela referida legislação. Na visão de Gonçalves e Pereira (2013, p.38), essa legislação constitui-se numa "oportunidade elementar para a escola revisar sua cultura, organização e trabalho, a fim de criar um espaço onde as múltiplas vozes sejam ouvidas e as diferenças sejam valorizadas".

$\mathrm{O}$ argumento para a inclusão dessa temática na prática pedagógica da escola consiste em que, historicamente, o currículo escolar, especialmente o de história, vem se concentrando numa história eurocêntrica, que privilegia como sujeito o homem branco, ocidental, burguês e católico, silenciam-se outros sujeitos, como mulheres, índios, asiáticos e, sobretudo, os africanos. Tal silêncio é sem dúvida uma forma de apagamento da cultura dos negros e 
negras, além de propiciar a criação de preconceitos. Nesse sentido, os autores citados acima consideram que:

\begin{abstract}
A dinâmica destas relações baseava-se, na maioria das vezes, em uma profunda ausência de referenciais positivos em relação à população afrobrasileira, um silêncio no que diz respeito à sua história e a produção de imagens estereotipadas sobre este grupo étnico. Esta postura fez com que a instituição escolar, às vezes, sem perceber, contribuísse para naturalização de um quadro de desigualdade histórico e socialmente construído, colaborando para manutenção de uma tessitura social onde as diferenças tornam-se desigualdades. (GONÇALVES; PEREIRA, 2013, p. 39).
\end{abstract}

A educação constituiu-se por décadas numa prática de produção e reprodução de preconceitos e formas discriminatórias racistas que atingiram diretamente os estudantes negros. A mudança na LDB de 1996, proposta pela Lei 10.639/03, foi prevista com o objetivo de visibilizar a história e a cultura dos afro-brasileiros no currículo escolar, proporcionando, assim, a valorização e a própria identificação desse grupo étnico-racial no contexto educacional.

De acordo com Gonçalves e Pereira as novas determinações dos artigos 26A e 79B da

LDB apresentam proposições para um novo arranjo nas práticas educativas com a mudança do paradigma em que a escola

[...] acaba por negar os valores, costumes e saberes de outros grupos e suas respectivas culturas, diminuindo as possibilidades de trabalho com uma pedagogia multicultural, que promova em seu interior relações baseadas no respeito e na igualdade de condições entre os diferentes grupos presentes na sociedade brasileira. (GONÇALVES; PEREIRA, 2013, p. 40).

A sanção dessa Lei e a aprovação das DCNERER representam o resultado de um longo processo histórico e político e da luta antirracista. O conteúdo da lei é antigo no movimento negro, evidencia como a escola vem reproduzindo a cultura de um determinado segmento da sociedade e significa o reconhecimento pelo Estado da necessidade da escola reavaliar o seu papel frente à diversidade étnico-cultural presente em seu contexto social. $\mathrm{Na}$ opinião de Gonçalves e Pereira, o conteúdo dessa legislação apresenta

novos parâmetros à constituição do conjunto de saberes veiculado pela instituição, através de práticas educativas, organização docente e materiais didáticos, a fim de que ela possa contar novas narrativas, construir outros símbolos e reproduzir patrimônios pertencentes aos diferentes grupos étnicos da sociedade brasileira. (GONCALVES ; PEREIRA, 2013, p. 39) 
Nesse sentido, a inclusão dos estudos sobre a História e Cultura Afro-brasileira e Africana não se restringe somente à inclusão dessa temática no currículo escolar. A proposta implica no estudo e exploração da diversidade do continente africano, da variedade cultural, das relações políticas e econômicas que incidiram forçosamente na saída dos africanos para lugares distantes. Implica em conhecer a trajetória da população negra na história da formação da nação brasileira, para que ela possa ser reavaliada, resignificada e valorizada, como descreve Cunha Júnior:

[...] A educação, os sistemas educacionais, em particular as escolas, têm como uma das finalidades permitir a compreensão de quem somos nós, como cada um de nós se situa na sociedade e na cultura nacional, como cada um de nós reconhece sua cidadania, os direitos e deveres no seio da comunidade nacional. Devido à importância estrutural que o africano tem na formação do país, é que nossa compreensão de povo brasileiro e da história nacional deve ter como base o conhecimento na história africana. (CUNHA JÚNIOR, 2013, p. 29).

O silêncio no currículo escolar sobre a Cultura e a História da África, sobre a História dos Africanos e dos Afrodescendentes, que estiveram presentes em diversos aspectos na formação do Brasil, reforça os preconceitos raciais e a não identificação dos negros com a educação escolar brasileira. Esse silêncio, segundo Cunha Júnior, impossibilita o conhecimento e o entendimento do porquê os africanos, ou os negros, foram escravizados, por que foram rendidos na África e transportados em condições sub-humanas como escravos para o Brasil. Boa parte dos comportamentos racistas e preconceituosos se fundamenta no desconhecimento da história e cultura dos africanos e afrodescendentes.

As mudanças ocorridas na LDB pela Lei 10.639/03 e as DCNERER abordam aspectos interpretativos sobre a identidade nacional com pressupostos não eurocêntricos, propondo ampliar o foco do currículo escolar, mas não se trata de mudança de um foco eurocêntrico para afrocêntrico, como observa Gonçalves e Pereira:

[...] não se trata de inverter a lógica das relações de poder através de transferência de privilégios nos processos de produção simbólica e representações de identidade. Mas sim criar possibilidades para que todos os sujeitos presentes no cotidiano possam, a partir das experiências pedagógicas, reconhecer suas diferenças nessas atividades e se sentirem parte da cultura escolar. (GONÇALVES; PEREIRA, 2013, p. 41). 
Nessa perspectiva, os autores consideram que as mudanças na LDB e as DCNERER oferecem subsídios para se pensar numa educação para as relações étnico-raciais que possibilite a valorização e a compreensão do diferente, sem desqualificá-lo, permitindo que o estudante afrobrasileiro valorize o seu pertencimento étnico-racial. Uma educação que proporcione condições para que os estudantes de outros grupos étnicos possam ter uma nova visão da população afrobrasileira.

Assim, Silva (2011) considera que a educação das relações étnico-raciais "enquanto processo pedagógico questiona a pretensão de que viveríamos numa sociedade monocultural, unificada por uma língua única, a uma só cultura a que todos os habitantes da nação deveriam convergir". Pondera que o questionamento se estende para a crença na inferioridade dos diferentes, sustenta-se em mitos que geram medos, criam desrespeito e desqualificação. A autora considera que "essas não verdades, que criam este estado, transformaram-se em verdades, e justamente o ensino da história da África e do afro-brasileiro são meios que temos para transformar essas verdades sem classificação e sem hierarquia" (2011, s.p.).

Nesse sentido, um dos grandes desafios que se evidenciam é a formação inicial de professores, na perspectiva da dimensão conflituosa das relações étnico-raciais presentes no contexto escolar, fundamentando-se numa visão complexa e sistêmica da realidade da diversidade étnico-cultural da população brasileira.

\section{Os caminhos da pesquisa e os resultados}

A pesquisa foi realizada numa instituição pública de ensino superior localizada no norte do Estado de Minas Gerais. O estudo foi realizado por meio de análise documental e entrevistas semiestruturadas, gravadas com o consentimento dos participantes, possibilitando assim, uma análise mais detalhada dos dados. Foram realizadas entrevistas com os gestores da Pró-Reitoria de Ensino, de Extensão e de Pesquisa - Unidades Administrativas selecionadas em função da natureza do trabalho que realizam junto aos cursos de graduação -, com os coordenadores dos cursos de Licenciatura em Artes-Música, Artes-Teatro, Artes-Visuais, História, Letras e Pedagogia, bem como com quatro professores de cada curso, com o propósito de verificar e analisar as ações que vem sendo desenvolvidas pela IES, no sentido de atender as DCNERER.

A IES analisada oferece dezessete cursos de licenciatura em diversas áreas do conhecimento. Para a concreção da pesquisa, foram tomados como amostra os cursos de 
Artes-Música, Artes-Teatro, Artes Visuais, História e Letras, por serem consideradas pela Lei 10639/03 como áreas do conhecimento privilegiadas para a abordagem da temática da Educação para as Relações Étnico-Raciais. Incluímos ainda, como base de análise, o curso de Pedagogia, pelo fato de formar professores para trabalhar com todas as áreas de conhecimento nas séries iniciais do Ensino Fundamental. O estudo caracteriza-se por uma metodologia de abordagem qualitativa.

Os dados levantados apontaram que as DCNERER não foram ainda institucionalizadas na Estrutura Curricular dos cursos de licenciatura analisados. Esse processo ainda se encontra em fase de implementação. Passados mais de onze anos de publicação das DCNERER, nos seis cursos de licenciatura analisados, o processo de sua implementação ainda é muito pontual. Os dados da pesquisa indicam problemas com uma inclusão normativa, que depende de muitos e muitos passos para que seja bem sucedida, sobretudo a politização que envolve os conhecimentos que serão privilegiados no currículo escolar. No caso analisado, a inclusão de uma nova temática no currículo escolar é considerada como um conhecimento secundário, não ocupando, assim, um espaço relevante no currículo acadêmico, envolve uma dinâmica delicada que implica em abrir brechas para inserção na estrutura curricular de um novo conhecimento imposto por uma normativa legal.

Outro aspecto que contribui para que a implementação das DCNERER não esteja a contento é o desconhecimento dessa legislação e principalmente dos seus objetivos: Ensinar o quê? Qual conhecimento será considerado no currículo escolar? Os dados da pesquisa apontaram que ainda não há uma clareza sobre o conhecimento relacionado a essa temática a ser trabalhado no currículo escolar. O estudo revelou que os documentos oficiais, Plano de Desenvolvimento Institucional (PDI), Projeto Político Pedagógico Institucional (PPPI) e Projeto Político Pedagógico (PPP) dos cursos analisados ainda não apresentam com clareza a inserção ou a previsão de ações ou metas a serem desenvolvidas para o processo de implementação da Educação para as Relações Étnico-Raciais. Consideramos que, se os documentos oficiais da instituição que norteiam o ensino na graduação (PDI e PPPI) estivessem sendo organizados com a previsão dessas ações, os PPPs dos cursos, consequentemente, também as contemplariam, uma vez que esses documentos são referências no processo de elaboração e atualização dos PPPs dos cursos de graduação. Para além da atuação docente, considerada estratégica para que as questões étnico-raciais cheguem às salas de aula, os órgãos gestores e a comunidade acadêmica desempenham papel fundamental no sentido de promover ações que viabilizem condições para que os espaços de formação 
docente se organizem para inclusão das temáticas relativas às relações étnico-raciais, bem como o ensino de História e Cultura Afro-Brasileira no processo de formação de seus profissionais.

\section{As ações da Extensão}

A entrevista e a análise documental realizadas junto à Pró-Reitoria de Extensão revelaram que esse setor vem desenvolvendo projetos que tratam da temática das relações étnico-raciais, começou com o Programa Integrado de Ações Afirmativas para Afrodescendentes (Afroatitude) ${ }^{3}$, desenvolvido no ano de 2005. No período de 2009 a 2013, a Extensão ofertou cursos de formação continuada para professores da Educação Básica, na perspectiva da Educação para as Relações Étnico-Raciais em parceria com o governo federal, com recursos captados por meio de edital. Os cursos ofertados foram: "Educação para as Relações Étnico-Raciais" "Gênero e Diversidade na Escola” e Educação na Diversidade e Cidadania".

Assim como em outras universidades públicas do país, observamos que em 2008 foi criado o NEAB (Núcleo de Estudos Afrobrasileiros), no âmbito da Pró-Reitoria de Extensão, com o propósito de vir a ser o espaço de articulação e desenvolvimento de atividades para criação e disseminação de práticas e/ou ações afirmativas para os negros na área de abrangência da IES analisada. Dessa forma, por meio do NEAB foi possível firmar parcerias com o governo federal para realização de ações voltadas para a temática da Educação para as Relações Étnico-Raciais, como a oferta do "UNIAFRO",. Esses cursos foram ofertados em duas edições em 2013 e 2014 com recursos captados por meio de editais.

Em 2015, as atividades do NEAB estavam voltadas para oferta de cursos integrantes das ações da campanha "Afroconsciência: com isso a escola tem a ver", lançada pela Secretaria Estadual de Educação de Minas Gerais (SEE/MG), com o objetivo de promover a articulação e a mobilização dos professores das escolas públicas para fortalecer a implementação e a efetividade da Lei 10639/03.

\footnotetext{
${ }^{3}$ Programa Brasil Afroatitude, financiado pelo governo federal por meio de edital, tinha como propósito beneficiar alunos afrodescendentes cotistas pro meio de oferta de bolsas de iniciação científica para participação em projetos de ensino, pesquisa e extensão, voltados para temáticas específicas para esse segmento da população.

${ }^{4}$ Curso de Formação Continuada para Professores da Educação Básica sobre as Relações Étnico-Raciais e Ensino de História e Cultura Afro-Brasileira.
} 
Conforme as DCNERER (BRASIL, 2004), os NEABs são considerados de grande importância nas IES para a pesquisa, a produção de material e a formatação de cursos visando a formação de professores para a diversidade étnico-racial. A despeito da realização de relevantes ações ${ }^{5}$ relativas às questões étnico-raciais, por problemas institucionais ${ }^{6}$, não houve um fortalecimento do NEAB e as ações desenvolvidas por esse Núcleo não contribuíram para que as DCNERER chegassem até os cursos de graduação. Os Coordenadores de Curso e os Professores disseram que nunca houve uma orientação ou direcionamento desse Núcleo no que diz respeito às mudanças no currículo dos cursos para a inserção da Educação para as Relações Étnico-Raciais.

A Pró-Reitoria de Extensão da IES analisada promove ações importantes no sentido de promover a formação continuada de professores da Educação Básica sobre a questão da Educação para as Relações Étnico-Raciais, em atendimento às DCNERER, com projetos financiados pelo Governo Federal e Estadual, com data de início e término. Com a finalização dos projetos, as ações não continuam por falta de recursos e pelo fato das temáticas trabalhadas nos cursos não terem sido inseridas na estrutura curricular dos cursos de graduação e nem nas diretrizes curriculares da graduação da instituição, objetivo principal das DCNERER.

\section{As ações da Pesquisa}

Ao nos debruçarmos sobre as ações da Pró-Reitoria de Pesquisa, observamos que o trabalho desenvolvido por essa unidade administrativa está voltado para o apoio aos grupos de pesquisa da instituição e de iniciação científica dos acadêmicos cotistas e não cotistas. Existe um consistente trabalho de pesquisa desenvolvido pelos professores nos grupos de pesquisa da universidade relacionados à população negra, como estudos sobre comunidades tradicionais, quilombolas, bem como estudos sobre a diversidade cultural presentes na região norte-mineira. São estudos e trabalhos no âmbito da pesquisa que envolvem professores e acadêmicos nos diversos cursos, produzindo materiais, artigos e realizando ações no sentido de dar visibilidade a esse segmento da população. Ao que parece, falta ainda a estruturação institucional de ações e articulações mais concretas para que os trabalhos que vêm sendo

\footnotetext{
${ }^{5}$ As ações realizadas pelo NEAB estavam registradas nos relatórios elaborados pelos professores participantes desse projeto, referentes ao período de 2008 a 2010. No período de 2011 a 2012 não havia registros das ações realizadas. Em 2013 e 2014 as ações do NEAB são voltadas para a oferta do Uniafro.

${ }^{6}$ No ano de 2011, o NEAB passou por um processo desestruturação em função da morte do coordenador, situação agravada em 2012 pelo afastamento de 04 professoras para o processo de doutoramento.
} 
desenvolvidos nesses grupos de pesquisa possam ser interligados, ou com a Pró-Reitoria de Ensino, ou com a coordenação e professores dos cursos de licenciatura, ou outras ações diretamente com as licenciaturas, no sentido de fazer com que esses conhecimentos produzidos cheguem até lá com maior frequência e maior intensidade.

\section{As ações do Ensino}

A pesquisa evidenciou que as ações da Pró-Reitoria de Ensino, em observância às DCNERER, são realizadas pelo trabalho dos assessores ${ }^{7}$ que orientam e acompanham todos os cursos nesse sentido. É realizado um trabalho de assessoria para a inserção das exigências dessa legislação nos PPPs e a cobrança para a realização de tal procedimento. O trabalho dos assessores da Pró-Reitoria de Ensino é realizado por meio do Núcleo Docente Estruturante (NDE) dos cursos de graduação. O NDE é uma instância recém criada, ele foi regulamentado no mês de abril de 2015, composto por parte dos professores do colegiado do curso, tendo como presidente o coordenador do referido. Assim, o trabalho de assessoria relatado também é recente e ainda não suficiente para produzir as mudanças requeridas pela legislação, visando a reorientação dos cursos de graduação e da formação dos professores.

A inserção da Educação para as Relações Étnico-Raciais e do Ensino de História e Cultura Afro-Brasileira e Africana demanda uma reorganização do contexto acadêmico, do currículo, das práticas pedagógicas e das relações sociais que ali são estabelecidas. Na visão do Pró-Reitor de Ensino, a ressignificação desse contexto não está ocorrendo. A realidade descrita aponta os conflitos que geram a aplicação de uma política de ação afirmativa, que é determinada por força de lei. Na visão do entrevistado, as DCNERER estão sendo inseridas nos PPPs dos cursos por causa da cobrança do Conselho Estadual de Educação. Ao que parece, está sendo uma medida para se fazer cumprir uma determinação legal. Sabemos que uma lei por si só não transforma uma realidade, as DCNERER, na visão de Mattos (2008), serão o que as escolas e seus profissionais fizerem com elas.

\section{A materialização das DCNERER nos cursos de licenciatura}

A pesquisa apontou que os currículos dos cursos de licenciatura de Artes/Música, Artes/Teatro e Artes/Visuais, História, Letras e Pedagogia ainda são constituídos por uma

\footnotetext{
${ }^{7}$ Profissionais da Educação que são lotados nessa unidade administrativa.
} 
tradição eurocêntrica, marcada pela predominância dos conhecimentos específicos da área de formação, relacionados com o currículo nacional comum em detrimento de outros saberes, como o continente africano e suas diversas manifestações culturais, a cultura afro-brasileira, as questões étnico-raciais, a diáspora e outros mais previstos pelas DCNERER. Ainda assim, não seria possível dizer que as DCNERER não foram ainda consideradas. Os estudos realizados constataram um crescente envolvimento dos professores nas suas práticas pedagógicas para a inserção das questões étnico-raciais em sala de aula e nas atividades acadêmicas, no contexto da instituição e no contexto social, como escolas da Educação Básica e em comunidades tradicionais. Nos cursos analisados, ocorre um nível de inserção das DCNERER em graus variados, em função do trabalho que vem sendo desenvolvido pelos professores.

No curso de História, no período de 2003 a 2013, as determinações das DCNERER não estavam presentes no currículo oficial (Ementas das disciplinas). Estas se faziam presentes de forma muito pontual no currículo formal (Plano de Ensino), que foi planejado por alguns professores para ser trabalhado em sala de aula, e também por meio da oferta de uma disciplina optativa, que vem sendo trabalhada, esporadicamente, sem uma proposta oficial de um conteúdo específico, sendo este elaborado pelo professor ao ofertar a disciplina, ocasionando, possivelmente, uma abordagem da temática conforme o conhecimento e entendimento do professor sobre as orientações das DCNERER. Em 2013, a disciplina optativa passou a ser obrigatória, foi inserida no currículo oficial, no $8^{\circ}$ período do curso, para as novas turmas ingressantes. Como as novas turmas entraram no segundo semestre de 2013, a disciplina será ofertada, portanto, no ano de 2017. Nesse intervalo, a discussão das DCNERER continuará acontecendo para as turmas que ingressaram até o primeiro semestre de 2013, caso a disciplina optativa seja eleita pelos alunos, e nas aulas de alguns poucos professores mais envolvidos com a discussão, que buscam relacionar os conteúdos das disciplinas com a temática das DCNERER.

Constatou-se que, o curso de Pedagogia, até o final do segundo semestre de 2015, não havia promovido a inserção das DCNERER no currículo do curso. Não havia ainda uma disciplina específica e/ou optativa destinada ao estudo das questões étnico-raciais. Tal processo estava em andamento no final do segundo semestre de 2015. Tal discussão ocorre, de maneira pontual, nas disciplinas de Fundamentos e Metodologia do Ensino de História e Educação e Diversidade, na dependência da sensibilidade e interesse dos docentes pela questão. Como no curso de História, no curso de Pedagogia, o conteúdo proposto pelas 
DCNERER se faz presente nas aulas e atividades acadêmicas de um grupo muito pequeno de professores mais engajados com as questões étnico-raciais.

O curso de Letras, foi o único a receber orientações do CEE/MG para a necessidade de implementação da Lei 10.639/03 e seus dispositivos legais. A partir das orientações do CEE/MG por ocasião da avaliação desse curso no ano de 2010, um desdobramento pôde ser observado durante a pesquisa em relação a organização dos outros cursos (Artes, História e Pedagogia) na direção de contemplar em seus currículos a orientação do CEE/MG. A expectativa era atender a exigências que seriam cobradas em uma nova avaliação desse órgão a esses cursos que seria realizada em 2015.

As mudanças no PPP do curso de Letras para a implementação das orientações das DCNERER ocorreram no ano de 2010. No período anterior a esse ano, não havia nenhuma discussão sobre as questões étnico-raciais na Estrutura Curricular do curso. Na reformulação do PPP, ocorrida no ano de 2010, foi inserida uma disciplina optativa destinada a tratar essa temática, sendo que a disciplina só seria ofertada se fosse escolhida pelos alunos.

No ano de 2015, o curso de Letras seria novamente avaliado pelo CEE/MG e, no processo de organização para essa avaliação, descobriu-se que a disciplina não atendia aos objetivos para os quais foi criada. No período de realização da nossa pesquisa, segundo semestre de 2015, essa disciplina havia sido reformulada e estava em processo de tramitação para aprovação. No relatório da visita do CEE/MG, ocorrida no final do segundo semestre de 2015, foi relatado que o curso havia se organizado para a inserção da Lei 10.639/03, passando a vigorar a partir do primeiro semestre de 2016.

No curso de Letras, os professores que trabalharam com a disciplina optativa e os professores da área de literatura, por entenderem a necessidade de se abordar as questões étnico-raciais nos cursos de formação de professores estão promovendo de forma muito pontual a implementação das orientações expressas nas DCNERER. Acredita-se que existe uma intenção de se fazer cumprir a legislação, mas ainda percebem-se algumas dificuldades no processo de inserção dessa temática nos cursos do Ensino Superior.

A pesquisa revelou que os cursos de Artes/Música, Teatro e Visuais também não institucionalizaram as DCNERER nos PPPs, esse processo encontra-se em andamento. A temática vem sendo trabalhada de forma pontual, por poucos professores, em função de um entendimento da necessidade da presença da discussão da diversidade cultural e étnico-racial no contexto de formação dos professores de Artes nas três áreas. 


\section{Considerações finais}

Oficialmente, as DCNERER não foram implementadas nos PPPs dos cursos de Artes/Música, Artes/Teatro, Artes/Visuais. Nos cursos de História, Letras e Pedagogia, as orientações das DCNERER encontram-se timidamente representadas por disciplinas optativas ou por disciplinas que discutem a diversidade na educação de forma mais ampla, abrangendo assim a diversidade étnico-cultural. No entanto, a pesquisa revelou que a temática expressa na Lei 10639/03 e nas DCNERER vêm sendo implementadas pelas ações docentes. São ações pontuais, desenvolvidas pelos professores, nas disciplinas em que trabalharam, por opção pessoal, por opção política, por compreender a necessidade de se trabalhar com essa temática na formação inicial de professores, por ser pesquisador na área, enfim por diversos outros motivos. São ações esparsas, individualizadas, que convivem com situações em que outros professores, mesmo trabalhando com a mesma disciplina, só abordam e discutem com os alunos o que está previsto no ementário da disciplina, em função de não ter ocorrido ainda de forma oficial a inserção da temática das DCNERER na Estrutura Curricular dos cursos.

Os estudos sinalizam uma previsão de transformação dessa realidade a partir do ano de 2016, em função das mudanças que já haviam sido realizadas ou estavam ocorrendo nos PPPs dos cursos no final do segundo semestre de 2015. São processos demorados, e dificilmente o estabelecimento de uma data dissolve a dimensão irregular, assimétrica e conflitiva que políticas públicas provocam nos ambientes onde são implantadas.

\section{Referências}

ABREU, Martha; MATTOS, Hebe. Em torno das "Diretrizes curriculares nacionais para a educação das relações étnico-raciais e para o ensino de história e cultura afro-brasileira e africana": uma conversa com historiadores. Estudos Históricos, Rio de Janeiro, v. 21, n. 41, p. 5-20, jan./jun., 2008.

ALBERTI, Verena; PEREIRA, Amilcar Araújo. Movimento negro e "democracia racial" no Brasil: entrevistas com lideranças do movimento negro. Rio de Janeiro: CPDOC, 2005.

BRASIL. Lei 10.639, de 09 de janeiro de 2003. D.O.U, de 10/01/2003.

BRASIL. Lei 11.645, de 10 de março de 2008. D.O.U, de 11/03/2008.

BRASIL. Lei no 9.394. LDB - Lei de Diretrizes e Bases da Educação Nacional, de 20 de dezembro de 1996. D.O.U, de 23 de dezembro de 1996. Disponível em www.mec.gov.br. Acesso em 30 de março de 2016. 
BRASIL. Ministério da Educação. Diretrizes Curriculares Nacionais para a Educação das Relações Étnico-Raciais e para o Ensino de História e Cultura Afro-Brasileira e Africana. CNE/CP 01/2004, 17 de junho de 2004.

BRASIL. Ministério da Educação. Parecer CNE/CP 3/2004, de 10 de março de 2004.

BRASIL. Ministério da Justiça. Decreto no 4228 de 13 de maio de 2002. Disponível em www.planalto.gov.br. Acesso em 17 de abril de 2016.

BRASIL. Constituição da República Federativa do Brasil (1988). Promulgada em 05 de outubro de 1988. Disponível em www.planalto.gov.br. Acesso em 28/04/2017.

BRASIL. Ministério da Educação. Secretaria de Educação Fundamental. Parâmetros Curriculares Nacionais. Brasília: MEC/SEF, 1998.

CAVALLEIRO, Eliane. Do silêncio do lar ao silêncio da escola: racismo, preconceito e discriminação na educação infantil. 6. ed. São Paulo: Contexto, 2012.

CUNHA JÚNIOR, Henrique. Diversidade etnocultural e africanidades. In: JESUS, Regina de Fátima; ARAÚJO, Mairce da Silva; JÚNIOR, Henrique Cunha (Org.). Dez anos da Lei no 10639/03: memórias e perspectivas. Fortaleza: UFC, 2013.

FERREIRA, Maria Claudia Cardoso. Formação para as relações Étnico-Raciais e a profissionalização em história: saberes e práticas docentes no contexto da educação a distância. Programa de pós-graduação em história, política e bens culturais. CPDOC. Tese de doutorado. Rio de Janeiro, 2013.

GOMES, Nilma Lino. Educação cidadã, etnia e raça: o trato pedagógico da diversidade. In: CAVALLEIRO, Eliana (Org.). Racismo e anti-racismo na educação: repensando nossa escola. São Paulo: Selo Negro, 2001.

GONÇALVES, Maria Alice Rezende (Org.). Sistema de reserva de vagas na Universidade do Rio de Janeiro e as ações do Núcleo de Estudos Afro-Brasileiros da UERJ. In: AhyasSiss (Org.). Diversidade Étnico-Racial e Educação Superior Brasileira: experiências de intervenção. Rio de Janeiro: Quartet, 2008.

GONÇALVES, Maria Alice Rezende (Org.). Educação, Cultura e Literatura AfroBrasileira: contribuições para a discussão racial na escola. Rio de Janeiro: Quartet / NEABUERJ, 2007.

GONÇALVES, Maria Alice Rezende; PEREIRA, Vinicius Oliveira. O contexto histórico das políticas racializadas e a emergência de novas etnicidades e a emergência do discurso "racializado" no sistema de ensino: as possibilidades e desafios da Lei 10.639/03. In: Teias, v. 13, n.34, 191-196, 2013: os 10 anos da Lei 10639/03 e a Educação.

GUIMARÃES, Antônio Sergio Alfredo. Preconceito racial: modos, temas e tempos. São Paulo: Cortez, 2008. 
JACCOUD, Luciana. Racismo e República o debate sobre o branqueamento e a discriminação racial no Brasil. In: THEODORO, Mário et al. (Org.). As políticas públicas e a desigualdade racial no Brasil: 120 anos após a abolição. Brasília: IPEA, 2008.

MÜLHER, Maria Lúcia Rodrigues. A cor da escola: imagens da Primeira República. Cuiabá, MT: Entrelinhas - UFMT, 2008.

MUNANGA, Kabengele. Rediscutindo a mestiçagem no Brasil: identidade nacional versus identidade negra. 3. ed. Belo Horizonte: Autêntica, 2008.

OLIVEIRA, Iolanda. Prefácio. In: MÜLHER, Maria Lúcia Rodrigues. A cor da escola: imagens da Primeira República. Cuiabá, MT: Entrelinhas - UFMT, 2008.

PEREIRA, Amilcar Araújo. O mundo negro: relações raciais e a constituição do movimento negro contemporâneo no Brasil. Rio de Janeiro: Pallas - FAPERJ, 2013.

SANTOS, Angela Maria. Vozes e silêncio no cotidiano escolar: as relações raciais entre alunos negros e não-negros. In: MÜLHER, Maria Lúcia Rodrigues; COSTA, Candida Soares (Org.). Coletânea Educação e Relações Raciais 4. Cuiabá: UFMT, 2007.

SILVA JUNIOR, Hédio. Notas sobre sistema jurídico e intolerância religiosa no Brasil. In: SILVA, Vagner Gonçalves (org.). Intolerãncia religiosa: impactos do neopentecostalismo no campo religioso afro-brasileiro. São Paulo. EDIUSP, 2007.

SILVA, Petronilha Beatriz Gonçalves. Coleção HGA: possibilidades para metodologias emancipatórias. Palestra proferida na cerimônia de lançamento da coleção HGA realizada em São Paulo, em 06 de abril de 2011. Disponível em: 〈www.unesco.org〉. Acesso em: 14 set. 2015.

SOUZA, Celina. Políticas públicas: uma revisão da literatura. Sociologias, Porto Alegre, ano 8, n. 16, jul./dez. 2006, p. 20-45.

SILVA, Adriana Maria Paulo da Silva. Reiventando um passado:diversidade étnica e social dos alunos das aulas públicas de primeiras letras no corte na primeira metade do século XIX. In: IOLANDA, de Oliveira. Cadernos Penesb - Periódico do Programa de Educação sobre o Negro na Sociedade Brasileira - FEUFF. n. 8, dezembro, 2006. Rio de Janeiro: Quartet / Niterói: UFF, 2006.

SCHWARCZ, Lilia Moritz. Nem preto nem branco muito pelo contrário: cor e raça na sociabilidade brasileira. 1. ed. São Paulo: Claro Enigma, 2012.

THEODORO, Mário. A formação do mercado de trabalho e a questão racial no Brasil. In: THEODORO, Mário et al (Org.). As políticas públicas e a desigualdade racial no Brasil: 120 anos após a abolição. Brasília: IPEA, 2008.

UNIMONTES. Departamento de História. Projeto Político Pedagógico Curso de História. Montes Claros, 2004.

UNIMONTES. Departamento de História. Projeto Político Pedagógico Curso de História. Montes Claros, 2013. 
UNIMONTES. Departamento de História. Plano de Ensino disciplina História da África. Curso de História, 1/2014.

UNIMONTES. Departamento de História. Plano de Ensino disciplina História da África. Curso de História, 1/2015.

UNIMONTES. Departamento de História. Plano de Ensino disciplina História do Brasil Colônia II. Curso de História, 1/2014.

UNIMONTES. Departamento de Letras. Projeto Político Pedagógico do Curso de Letras/Português. Montes Claros, 2007.

UNIMONTES. Departamento de Letras. Projeto Político Pedagógico do Curso de Letras/Português. Montes Claros, 2010.

UNIMONTES. Projeto Político Pedagógico Curso de Pedagogia. Montes Claros, 2013.

UNIMONTES. Projeto Político Pedagógico Curso de Pedagogia. Montes Claros, 2007.

UNIMONTES. Departamento de Artes. Projeto Político Pedagógico Curso de Artes/Teatro. Montes Claros, 2005.

UNIMONTES. Departamento de Artes. Projeto Político Pedagógico Curso de Artes/Visuais. Montes Claros, 2011.

UNIMONTES. Departamento de Artes. Projeto Político Pedagógico Curso de Artes/Música. Montes Claros, 2005a.

UNIMONTES. Pró-Reitoria de Extensão. Relatório final de cumprimento do objeto Relatório UNIAFRO. Montes Claros, novembro, 2014.

UNIMONTES. Pró-Reitoria de Extensão. Relatório de atividades do curso Gênero de Diversidade na Escola. Montes Claros, novembro de 2011a.

UNIMONTES. Pró-Reitoria de Extensão. Relatório de atividades do curso Educação para as Relações Étnico Raciais. Montes Claros, novembro de 2011 b.

UNIMONTES. Pró-Reitoria de Extensão. Relatório de atividades do curso Educação para a Diversidade e Cidadania. Montes Claros, novembro de 2011c.

UNIMONTES. Pró-Reitoria de Ensino. Plano de Desenvolvimento Institucional - PDI 2010-2014. Montes Claros, 2010.

UNIMONTES. Pró-Reitoria de Extensão. Relatório de atividades projeto Unimontes Afroatitude. Montes Claros, 2007.

UNIMONTES. Pró-Reitoria de Ensino. Projeto Político Pedagógico Institucional. Montes Claros, 2011. 


\section{Dr $^{a}$ Zilmar Santos Cardoso}

Universidade Estadual de Montes Claros - Brasil Doutora em Ciências Sociais e Mestre em Educação Grupo de Estudos e Pesquisas de Educação Diversidade e Saúde (GEPEDS)

E-mail: zilmar.cardoso@ead.unimontes.br

Recebido em: 07 de outubro de 2016 Aprovado em: 25 de novembro de 2016 